\title{
Non-invasive diagnosis in clinically suspected atrial septal defect of secundum or sinus venosus type Value of combining chest x-ray, phonocardiography, and M-mode echocardiography
}

\author{
HENRIK EGEBLAD, JENS BERNING, FRITZ EFSEN, ALF WENNEVOLD \\ From the Cardiovascular Laboratory of Medical Department B and the Cardiovascular Section of \\ Department of Diagnostic Radiology, Rigshospitalet, Copenhagen, Denmark
}

SUMMARY Twenty-three consecutive patients with clinical (auscultatory and electrocardiographic) signs of uncomplicated atrial septal defect of secundum or sinus venosus type were examined by chest $x$-ray, phonocardiography, and echocardiography, before right heart catheterisation. Seventeen (74\%) had atrial septal defect, two patients $(9 \%)$ had insignificant pulmonary stenosis, and four subjects $(17 \%)$ were normal. No false positive diagnosis of atrial septal defect was made by chest $x$-ray examination, whereas increased vascular markings were incorrectly interpreted as pulmonary congestion in one case. Four patients had $x$-ray films showing questionable signs of left-to-right shunt. Six of 15 patients with a large left-to-right shunt were correctly selected for surgery based on radiological findings. One false negative but no false positive diagnosis of atrial septal defect was made by phonocardiography. Four cases with and four cases without atrial septal defect were classified as having questionable phonocardiographic signs of atrial septal defect. Echocardiographic distinction between those with atrial septal defect and those without atrial septal defect was correct in all cases; quantitative measurement of left-to-right shunt, however, was unsatisfactory. Combined normal findings by $x$-ray film and echocardiography appeared adequate in all cases for the exclusion of atrial septal defect (six patients). When the six patients who were correctly identified for surgery from the radiological findings are included, there was a total of 12 patients out of 23 (52\%:95\% confidence limits 31 to $73 \%$ ) who were evaluated definitively by the non-invasive tests.

The patient with fixed splitting of the second heart sound on auscultation, incomplete right bundlebranch block, and a normal electrocardiographic QRS axis frequently presents a diagnostic problem. Though suspicion of an atrial septal defect of the secundum or sinus venosus type in such patients will often prove justified, heart catheterisation in others will disclose no signs of atrial septal defect or any other structural abnormality. ${ }^{1}$ New techniques such as two-dimensional contrast echocardiography, ${ }^{23}$ ultrasonic Doppler examination, and radionuclide methods ${ }^{5}$ may become future routine examinations in suspected atrial septal defect. At present, however, chest $x$-ray examination, phonocardiography, and M-mode echocardiography are well established non-invasive Received for publication 31 December 1979 techniques readily available in most cardiac centres. $^{6-8}$ The purpose of the present study was to investigate the reliability of these techniques in the setting of clinically suspected uncomplicated atrial septal defect.

\section{Patients and methods}

During a one year period 23 consecutive patients with a clinical suspicion of atrial septal defect were referred for heart catheterisation. There were 14 male and nine female patients, range 5 to 48 years, mean 15 years. The patients were defined by a fixed splitting of the second heart sound on auscultation accompanied by a grade 1-2/6 systolic ejection murmur in the pulmonary area and incomplete or complete (case 17, Table) right bundle-branch 
block with a normal QRS axis. Patients suspected of pulmonary hypertension or structural abnormalities other than atrial septal defect were excluded from the study, based on physical examination and electrocardiogram. The day before heart catheterisation non-invasive examinations including chest $x$-ray, phonocardiography, and M-mode echocardiography were carried out and evaluated separately by three different observers. Each examiner was unaware of the results of the two other tests.

Chest $\mathrm{x}$-ray examination was performed in the erect position in the posteroanterior and lateral projections. Signs of increased pulmonary blood flow in patients with fixed splitting of the second heart sound and incomplete right bundle-branch block were considered diagnostic of atrial septal defect. Thus, patients with intrapulmonary vessels in the upper lung zones of increased calibre and readily visible to the peripheral edge of the lungs were classified as having atrial septal defect. ${ }^{6}$ Atrial septal defect requiring operation (see below) was diagnosed in those cases with intrapulmonary vessels of increased calibre in all lung zones. ${ }^{6}$ Equivocal findings were denoted as questionable atrial septal defect or questionable atrial septal defect requiring surgery, respectively.

Phonocardiography, with patients in $40^{\circ}$ recumbent position, was recorded during normal quiet respiration in the second left intercostal space at a paper speed of $100 \mathrm{~mm} / \mathrm{s}$ (Siemens-Elema Mingograph 62). A splitting of the second heart sound $\left(\mathrm{A}_{2} \mathrm{P}_{2}\right.$ interval) of more than $35 \mathrm{~ms}$ during normal expiration in combination with a variation in the splitting $\left(\mathrm{A}_{2} \mathrm{P}_{2}\right.$ variation) of less than $15 \mathrm{~ms}$ during normal respiration were considered diagnostic of atrial septal defect. ${ }^{7} 9$

Patients with $\mathrm{A}_{2} \mathrm{P}_{2}$ interval of $30 \pm 5 \mathrm{~ms}$ or $\mathrm{A}_{2} \mathrm{P}_{2}$ variation of $20 \pm 5 \mathrm{~ms}$, respectively, were classified as questionable atrial septal defect.

Echocardiography was recorded using either Aloka SSD-110 or Mediscan 30 ultrasonic apparatus interfaced to a Cambridge recorder. M-mode scans from apex to base were performed in the supine and left lateral positions with the transducer in the third, fourth, and fifth left intercostal spaces near the sternal border. A paper speed of $25 \mathrm{~mm} / \mathrm{s}$ was used, whereas interventricular septal motion was studied at the chordal level using 50 or $100 \mathrm{~mm} / \mathrm{s}$. Right ventricular end-diastolic dimension was measured in the supine position at the chordal level according to Feigenbaum $^{8}$ using the intercostal space with the largest right ventricular end-diastolic dimension (RVD). Measurements were corrected for body surface area (RVD Index $=\mathrm{RVD} / \mathrm{m}^{2}$ body surface). In the clinical context of this series, right ventricular volume overload was regarded as diagnostic of atrial septal defect and defined as the combination of abnormal septal motion ${ }^{10} 11$ and right ventricular dilatation (RVD Index of more than $1.4 \mathrm{~cm} / \mathrm{m}^{2}$ ). A case with an RVD Index more than $1.4 \mathrm{~cm} / \mathrm{m}^{2}$ together with normal septal motion, or abnormal septal motion in a patient with an RVD Index of less than $1.4 \mathrm{~cm} / \mathrm{m}^{2}$ was classified as questionable atrial septal defect. The type of septal motion ${ }^{10} 11$ was noted in all scans, but was evaluated definitively from the intercostal space with the largest right ventricular end-diastolic dimension. An M-mode scan from the tricuspid to the mitral valve was performed in each intercostal space in the supine and left lateral positions. The maximum diastolic separation of the tricuspid and of the mitral leaflets was measured in each tracing and their ratio $(\mathrm{T} / \mathrm{M})$ calculated according to Chiotellis et al. ${ }^{12}$ Maximum $\mathrm{T} / \mathrm{M}$ and maximum RVD Index were correlated to shunt size as determined by catheterisation.

Heart catheterisation was performed percutaneously via the right femoral vein. Pulmonary-tosystemic flow ratio was calculated by the oximetric method..$^{13}$ If no left-to-right shunt was demonstrable on oximetry the atrial septum was carefully probed to exclude a communication (two cases) or the hydrogen appearance time was measured.14

Patients with a flow ratio equal to or larger than 2.0 or a flow ratio larger than 1.8 in combination with cardiac enlargement were referred for operation. ${ }^{13}$

\section{Results}

A left-to-right shunt at atrial level was shown in $\mathbf{1 7}$ patients $(74 \%)$ while six patients $(26 \%)$ had no detectable atrial septal defect (Table). The left-toright shunt was small in two patients (flow ratio = 1.3 and 1.5 , respectively). The six patients without atrial septal defect included four with normal findings at right heart catheterisation and two patients with negligible valvular pulmonary stenosis (Table).

\section{CHEST $x$-RAY}

No false positive diagnosis of left-to-right shunt was made on chest $x$-ray. An increased flow pattern in a 48-year-old man was erroneously interpreted as pulmonary congestion (case 17, Table). Four cases with flow ratios ranging from 1.5 to more than 4 were classified as having questionable signs of left-to-right shunt, whereas a left-to-right shunt was predisted in a patient with a flow ratio of only 1.3. Six patients out of 12 with definite radiological signs of left-to-right shunt were correctly 
suggested as needing operation according to our present guidelines. ${ }^{13}$ The other six patients included three with questionable signs of a large shunt and three patients who were classified as having atrial septal defect not requiring operation, but, of the last-mentioned, two patients had flow ratios of more than 2.0 and were in fact referred for operation (Table).

\section{PHONOCARDIOGRAPHY}

Mean $\mathrm{A}_{2} \mathrm{P}_{2}$ interval $( \pm \mathrm{SD})$ in patients with atrial septal defect was $50.3 \pm 11.3 \mathrm{~ms}$; this was not significantly different from $\mathrm{A}_{2} \mathrm{P}_{2}$ interval in patients without atrial septal defect $(40 \cdot 8 \pm 12 \cdot 4 \mathrm{~ms} ; \mathrm{p}>0 \cdot 1$; $t$ test). Corresponding values of $\mathrm{A}_{2} \mathrm{P}_{2}$ variation were $10 \cdot 0 \pm 9 \cdot 2 \mathrm{~ms}$ in patients with atrial septal defect in contrast to patients without atrial septal defect who had $\mathrm{A}_{2} \mathrm{P}_{2}$ variation $=25 \cdot 8 \pm 7 \cdot 3 \mathrm{~ms}$ $(\mathrm{p}<0.01 ; \mathrm{t}$ test). One false negative (flow ratio 1.5$)$ but no false positive diagnosis was made by phonocardiography (Table). Four cases with and four cases without atrial septal defect were classified as questionable.

\section{ECHOCARDIOGRAPHY}

Patients with atrial septal defect had RVD Index = $2.8 \pm 0.6 \mathrm{~cm} / \mathrm{m}^{2}$ (mean $\pm \mathrm{SD}$ ), range 2.0 to 4.0 $\mathrm{cm} / \mathrm{m}^{2}$, in contrast to RVD Index $=1 \cdot 1 \pm 0 \cdot 2 \mathrm{~cm} / \mathrm{m}^{2}$, range 0.9 to $1.4 \mathrm{~cm} / \mathrm{m}^{2}$, in patients without atrial septal defect $(p<0.001 ; t$ test $)$. The localisation of the largest right ventricular end-diastolic dimension varied; it was obtained in the third intercostal space in six patients, in the fourth intercostal space in nine patients, and in the fifth intercostal space in eight patients. No false negative or false positive diagnosis was made (Table). The maximum ratio

Table Radiological, phonocardiographic, echocardiographic, and right heart catheterisation findings in 23 patients with clinical suspicion of atrial septal defect of secundum or sinus venosus type (ASD)

\begin{tabular}{|c|c|c|c|c|c|c|c|c|c|c|c|c|c|c|c|}
\hline \multirow{2}{*}{$\begin{array}{l}\text { Case } \\
\text { no. }\end{array}$} & \multirow{2}{*}{$\begin{array}{l}\text { Age } \\
(y)\end{array}$} & \multirow{2}{*}{ Sex } & \multicolumn{2}{|l|}{ X-ray } & \multicolumn{3}{|l|}{ Phono } & \multicolumn{4}{|l|}{ Echo } & \multicolumn{4}{|c|}{ Catheterisation } \\
\hline & & & $A S D$ & $O p$ & $\begin{array}{l}A_{2} P_{2} \\
(m s)\end{array}$ & $\begin{array}{l}A_{2} P_{2}-v a r \\
(m s)\end{array}$ & $A S D$ & $\begin{array}{l}R V D I \\
\left(\mathrm{~cm} / \mathrm{m}^{2}\right)\end{array}$ & $T / M$ & Smot & $A S D$ & $\begin{array}{l}R V P \\
(m m H g)\end{array}$ & $\begin{array}{l}P A P \\
(m m H g)\end{array}$ & $F R$ & Pathology \\
\hline 1 & 5 & $\mathbf{M}$ & + & + & 60 & 0 & + & $4 \cdot 0$ & $1 \cdot 3$ & $\mathbf{B} / \mathbf{N}$ & + & $30 / 3$ & $18 / 8$ & $2 \cdot 5$ & $\begin{array}{l}\text { Sinus venosus defect, } \\
\text { one abn pulm vein }\end{array}$ \\
\hline 2 & 8 & $\mathbf{M}$ & + & $?$ & 50 & 0 & + & $2 \cdot 6$ & $1 \cdot 6$ & $\mathbf{A} / \mathbf{B}$ & + & $26 / 4$ & $24 / 8$ & $1 \cdot 8$ & $\begin{array}{l}\text { Secundum defect (re- } \\
\text { quiring operation) }\end{array}$ \\
\hline 4 & 8 & $\mathbf{M}$ & + & - & 50 & 0 & + & $4 \cdot 0$ & $1 \cdot 4$ & $A / N$ & + & $25 / 6$ & $20 / 10$ & $3 \cdot 4$ & $\begin{array}{l}\text { Secundum defect, } \\
\text { one abn pulm vein }\end{array}$ \\
\hline 5 & 9 & $\mathrm{~F}$ & + & + & 60 & 10 & + & $2 \cdot 7$ & $1 \cdot 6$ & $\mathbf{A} / \mathbf{A}$ & + & $30 / 0$ & $20 / 4$ & $4 \cdot 0$ & Secundum defect \\
\hline 6 & 9 & $\mathbf{M}$ & + & - & 35 & 20 & $?$ & $2 \cdot 9$ & $1 \cdot 4$ & $\mathbf{B} / \mathbf{N}$ & + & $52 / 4$ & $50 / 8$ & $1 \cdot 3$ & $\begin{array}{l}\text { Secundum defect, } \\
\text { one abn pulm vein, } \\
\text { peripheral pul- } \\
\text { monary artery } \\
\text { stenoses }\end{array}$ \\
\hline 7 & 10 & $\mathbf{F}$ & $?$ & & 40 & 0 & + & $2 \cdot 6$ & 1.5 & $\mathbf{B} / \mathbf{N}$ & + & $30 / 6$ & $20 / 8$ & $2 \cdot 7$ & $\begin{array}{l}\text { Sinus venosus defect, } \\
\text { one abn pulm vein }\end{array}$ \\
\hline 8 & 11 & $\mathbf{M}$ & + & $?$ & 50 & 10 & + & $2 \cdot 6$ & $1 \cdot 5$ & $\mathbf{B} / \mathbf{N}$ & + & $26 / 6$ & $25 / 8$ & $2 \cdot 3$ & Secundum defect \\
\hline 9 & 11 & $\mathbf{F}$ & + & $?$ & 50 & 20 & $?$ & $2 \cdot 1$ & $1 \cdot 5$ & $\mathbf{B} / \mathbf{B}$ & + & $40 / 5$ & $27 / 8$ & $2 \cdot 3$ & Secundum defect \\
\hline 10 & 12 & $\mathbf{M}$ & $?$ & & 60 & 0 & + & $2 \cdot 0$ & $1 \cdot 2$ & $\mathbf{N} / \mathbf{B}$ & + & $38 / 6$ & $20 / 7$ & $2 \cdot 1$ & Secundum defect \\
\hline 11 & 13 & $\mathbf{M}$ & + & + & 50 & 10 & + & $2 \cdot 9$ & $1 \cdot 5$ & $\mathbf{B} / \mathbf{A}$ & + & $26 / 5$ & $20 / 7$ & $2 \cdot 2$ & $\begin{array}{l}\text { Sinus venosus defect, } \\
\text { one abn pulm vein }\end{array}$ \\
\hline 12 & 13 & $\mathbf{F}$ & $?$ & & 50 & 10 & + & $3 \cdot 8$ & $2 \cdot 5$ & $\mathbf{A} / \mathbf{A}$ & + & $46 / 4$ & $26 / 8$ & $>4 \cdot 0$ & Secundum defect \\
\hline 13 & 17 & $\mathbf{F}$ & + & - & 50 & 10 & + & $2 \cdot 0$ & 1.5 & $\mathbf{A} / \mathbf{A}$ & + & $27 / 4$ & $22 / 7$ & $2 \cdot 7$ & Secundum defect \\
\hline 14 & 18 & $\mathbf{F}$ & + & + & 25 & 25 & $?$ & $2 \cdot 2$ & $1 \cdot 4$ & $\mathbf{A} / \mathbf{B}$ & + & $28 / 7$ & $27 / 10$ & $3 \cdot 0$ & $\begin{array}{l}\text { Sinus venosus defect, } \\
\text { two abn pulm veins }\end{array}$ \\
\hline 15 & 25 & F & + & + & 45 & 15 & $?$ & $3 \cdot 0$ & 1.4 & A/B & + & $28 / 8$ & $28 / 10$ & $2 \cdot 3$ & Secundum defect \\
\hline 16 & 33 & $\mathbf{M}$ & $?$ & & 50 & 30 & - & $2 \cdot 3$ & $1 \cdot 3$ & $\mathbf{B} / \mathbf{B}$ & + & $31 / 3$ & $24 / 8$ & 1.5 & Secundum defect \\
\hline 17 & 48 & $M$ & - & & 80 & 0 & + & $3 \cdot 0$ & 1.5 & $\mathbf{A} / \mathbf{B}$ & + & $30 / 9$ & $30 / 10$ & $3 \cdot 4$ & Secundum defect \\
\hline 18 & 12 & $\mathbf{F}$ & - & & 35 & 25 & $?$ & $1 \cdot 0$ & 0.9 & $\mathbf{N} / \mathbf{N}$ & - & $32 / 4$ & $14 / 8$ & 1 & Small PS \\
\hline 19 & 14 & $\mathbf{F}$ & - & & 40 & 30 & - & $1 \cdot 4$ & $1 \cdot 2$ & N/B & - & $36 / 5$ & $18 / 8$ & 1 & Small PS \\
\hline 20 & 15 & $\mathrm{M}$ & - & & 40 & 20 & $?$ & $1 \cdot 2$ & $1 \cdot 0$ & $\mathbf{N} / \mathbf{N}$ & - & $27 / 3$ & $24 / 8$ & 1 & Normal \\
\hline 21 & 15 & $M$ & - & & 50 & 20 & $?$ & 0.9 & 0.9 & $\mathbf{N} / \mathbf{N}$ & - & $30 / 6$ & $26 / 10$ & 1 & Normal \\
\hline 22 & 17 & $\mathbf{M}$ & - & & 60 & 20 & $?$ & 0.9 & $1 \cdot 1$ & $\mathbf{N} / \mathbf{N}$ & - & $26 / 3$ & $22 / 6$ & 1 & Normal \\
\hline 23 & 20 & $M$ & - & & 20 & 40 & - & $1 \cdot 2$ & $1 \cdot 2$ & $\mathbf{N} / \mathbf{N}$ & - & $23 / 3$ & $23 / 9$ & 1 & Normal \\
\hline
\end{tabular}

A, A type of abnormal interventricular septum motion; $\mathbf{A}_{2} \mathbf{P}_{\mathbf{2}}$, interval between aortic and pulmonary component of second heart sound measured during normal expiration; $A_{2} P_{2}$-var, variation in splitting of second heart sound during normal respiration; $B$, $B$ type of abnormal interventricular septum motion; FR, pulmonary-to-systemic flow ratio; $\mathrm{N}$, normal interventricular septum motion; Op, signs of large left-to-right shunt requiring operation; PAP, pulmonary artery pressure; PS, valvular pulmonary stenosis; RVP, right ventricular pressure; RVDI, right ventricular end-diastolic diameter corrected for body surface area; Smot, type of interventricular septum motion; letter to the left of the diagonal stroke signifies septum motion in maximum RVD, whereas letter to the right represents septum motion found in one or more other projections. $T / \mathbf{M}$, maximum ratio between largest opening of the tricuspid and mitral valve; + , present; - , absent. 
between tricuspid and mitral leaflet separation ( $\mathrm{T} / \mathrm{M}$ ) was $1.5 \pm 0.3$ (mean $\pm \mathrm{SD}$ ) in patients with atrial septal defect and $1 \cdot 1 \pm 0 \cdot 1$ in patients without $(\mathrm{p}<0.001 ; \mathrm{t}$ test). A linear relation could be shown between flow ratio and $\mathrm{T} / \mathrm{M}(\mathrm{T} / \mathrm{M}=0.25 \times \mathrm{FR}+$ $0.85 ; r=0.80)$ and between RVD Index and flow ratio (RVD Index $=0.65 \times F R+0.95 ; r=$ 0.73). Patients with small left-to-right shunts (cases 6 and 16, Table) could not be specifically identified; these patients, however, had small $\mathrm{T} / \mathrm{M}$ values (Table). Septal motion varied within the same individual in most patients with atrial septal defect (Table). Normal motion was observed in either the third or fifth intercostal space in five patients with atrial septal defect.

\section{Discussion}

Though right heart catheterisation in older children and adults is a relatively simple procedure carrying only a minimal risk, it would of course be desirable to avoid this examination in healthy subjects with a clinical suspicion of atrial septal defect. Moreover, non-invasive identification of surgical candidates would save time and reduce costs. In our series, chest $x$-ray examination appeared satisfactory in excluding left-to-right shunt. Only one false negative interpretation was made. Increased vascular markings in this case were erroneously regarded as pulmonary congestion (case 17, Table); the patient, however, would of course not have been acquitted of heart disease on the basis of the radiological findings. Furthermore, combination of the radiological findings with phonocardiography and echocardiography would immediately have corrected the radiological diagnosis.

No false positive radiological diagnosis was suggested, but only questionable signs of left-toright shunt were described in four out of 17 patients with atrial septal defect including three patients with flow ratios of $2 \cdot 1,2 \cdot 7$, and more than 4 , respectively. Radiological markings suggesting need for operation seemed reliable; however, only six out of 15 such patients were identified. The radiological suggestion of a small atrial septal defect, on the other hand, correlated poorly with catheterisation data; one patient was correctly regarded as having a small shunt, whereas two patients with large shunts were erroneously classified as having small atrial septal defects not requiring operation.

Considering the setting including an auscultatory wide fixed splitting of the second heart sound, the phonocardiographic measurements of $\mathrm{A}_{2} \mathrm{P}_{2}$ interval and $A_{2} P_{2}$ variation provided relatively poor supplementary information for the exclusion of atrial septal defect in an individual patient as only two out of six patients could be excluded. All patients with $\mathrm{A}_{2} \mathrm{P}_{2}$ variation below $15 \mathrm{~ms}$ had atrial septal defect (12 out of 17 patients with atrial septal defect). These findings are in accordance with previous reports. ${ }^{79}$ Combining the results of these reports with our data, no better disciminating level of $\mathrm{A}_{2} \mathrm{P}_{2}$ variation than the value actually selected could be established. It is not surprising that exact measurement of the $\mathrm{A}_{2} \mathrm{P}_{2}$ interval was of minor value in the differentiation between atrial septal defect and non-atrial septal defect in these patients, who were initially defined by a wide splitting of the second heart sound on auscultation.

Echocardiography distinguished between uncomplicated atrial septal defect and non-atrial septal defect. The RVD Index limit of $1.4 \mathrm{~cm} / \mathrm{m}^{2}$ has been chosen based on published reports ${ }^{8} 101115$ and on experiences from our own laboratory. The RVD Index in combination with the pattern of septal motion appeared to be a good discriminator in our series. Other reports have shown the occasional appearance of a patient with atrial septal defect and a normal echocardiogram. These cases were all patients with small left-to-right shunts (flow ratio less than 2.0 ) or patients with pulmonary hypertension.11 1617 One should, however, be aware of a possible false negative echocardiogram. Moreover, echocardiograms indicating right ventricular volume overload in two normal patients have been reported. ${ }^{1}$ Thus, the addition of supportive information from phonocardiogram and chest $x$-ray examination is advisable.

Previous reports have shown either no or relatively poor correlation between RVD Index and flow ratio. ${ }^{10-12}$ The good correlation in our series may be the result of the consistent use of the largest right ventricular end-diastolic dimension. We have very limited data, however, concerning small defects not requiring operation, and the correlation found does not appear sufficient in selecting patients for surgery. Chiotellis et al.12 found a linear correlation $(r=0.57)$ between flow ratio and the ratio of the maximum opening of the two atrioventricular valves in 27 patients. Our high correlation coefficient of 0.80 may be explained by the systematic use of the maximum ratio comparing several transducer and patient positions. Still, the correlation does not appear adequate for definitive shunt evaluation. It should be realised that an increased $T / M$ ratio does not necessarily express an increased flow ratio, but may merely reflect right heart enlargement and facilitate visualisation of parts of the tricuspid valve not seen in normal subjects.

The considerable variation in type of septal motion within the same patient is noteworthy. This 
finding has been described by Kerber et al. ${ }^{18}$ in occasional patients, but appears from our series to be a common feature in patients with atrial septal defect; the degree of variation is probably dependant on the number of projections available.

\section{Conclusion}

Given an auscultatory and electrocardiographic suspicion of uncomplicated atrial septal defect, the combined finding of a normal chest $x$-ray film and a normal M-mode echocardiogram appears to indicate that there is no atrial septal defect. Phonocardiography seems to be of less value in excluding atrial septal defect.

Confirmation of an atrial septal defect was correctly obtained by echocardiography in all our cases and no false positive diagnosis was made either by radiological examination or by phonocardiography. Our data on small atrial septal defects with left-to-right shunts below the operative range are too limited to draw definite conclusions. It appears that a patient with echocardiographic findings of right ventricular volume overload, $\mathrm{A}_{2} \mathrm{P}_{2}$ variation below $15 \mathrm{~ms}$ during normal respiration, and a chest $x$-ray suggesting a large left-to-right shunt will, at right heart catheterisation, demonstrate the need for closing an atrial septal defect.

In our series of 23 patients with a clinical suspicion of atrial septal defect all six patients without defects were correctly excluded by chest $x$-ray and echocardiography. Six patients with atrial septal defect diagnosed by chest $x$-ray and echocardiography with a phonocardiographic confirmation in four cases were correctly selected for operation based on radiological findings. Thus, a total of 12 out of 23 patients $(52 \%: 95 \%$ confidence limits 31 to $73 \%$ ) appears to be definitely evaluated without heart catheterisation.

Improved non-invasive diagnostic results can perhaps be provided in the future using techniques such as radionuclide examinations and by developing ultrasonic methods.

\section{References}

1 Bahler AS, Meller J, Brik H, Herman MV, Teichholz LE. Paradoxical motion of the interventricular septum with right ventricular dilatation in the absence of shunting. Am F Cardiol 1976; 38: 654-7.

2 Fraker TD Jr, Harris PJ, Behar VS, Kisslo JA. Detection and exclusion of interatrial shunts by two-dimensional echocardiography and peripheral venous injection. Circulation 1979; 59: 379-84.
3 Weyman AE, Wann LS, Caldwell RL, Hurwitz RA, Dillon JC, Feigenbaum $H$. Negative contrast echocardiography. A new method for detecting left-to-right shunts. Circulation 1979; 59: 498-505.

4 Kalmanson D, Veyrat G, Derai C, Savier CH, Berkman M, Chiche P. Non-invasive technique for diagnosing atrial septal defect and assessing shunt volume using directional Doppler ultrasound. $\mathrm{Br}$ Heart $\mathcal{F}$ 1972; 34: 981-91.

5 Flaherty JT, Canent RV Jr, Boineau JP, Anderson PAW, Levin AR, Spach MS. The use of externally recorded radioisotope-dilution curves for quantitation of left-to-right shunts. Am $\mathcal{F}$ Cardiol 1967; 20: 341-5.

6 Simon $M$. The pulmonary vasculature in congenital heart disease. Radiol Clin North Am 1968; 6: 303-17.

7 Leatham A, Gray I. Auscultatory and phonocardiographic signs of atrial septal defect. Br Heart $\mathcal{f}$ 1956; 18: 193-208.

8 Feigenbaum H. Echocardiography. 2nd ed. Philadelphia: Lea \& Febiger, 1976.

9 Shafter HA. Splitting of the second heart sound. Am F Cardiol 1960; 6: 1013-22.

10 Diamond MA, Dillon JC, Haine CL, Chang S, Feigenbaum H. Echocardiographic features of atrial septal defect. Circulation 1971; 43: 129-35.

11 Radtke WE, Tajik AJ, Gau GT, Schattenberg TT, Guiliani ER, Tancredi RG. Atrial septal defect: echocardiographic observations. Studies in 120 patients. Ann Intern Med 1976; 84: 246-53.

12 Chiotellis P, Lees R, Goldblatt A, Liberthson R, Myers G. New criteria for echocardiographic diagnosis of atrial septal defect (abstract). Circulation 1975; 51 \& 52, suppl II : 135.

13 Andersen M, Lyngborg K, Møller I, Wennevold A. The natural history of small atrial septal defects: long-term follow-up with serial heart catheterizations. Am Heart f 1976; 92: 302-7.

14 Wennevold A. Hydrogen in the detection of minute left-to-right shunts. Scand f Clin Lab Invest 1966; 19: 181-5.

15 Pearlman AS, Borer JS, Clark CE et al. Abnormal right ventricular size and ventricular septal motion after atrial septal closure. Am $\mathcal{F}$ Cardiol 1978; 41: 295-301.

16 Tajik AJ, Gau GT, Schattenberg TT, Ritter DG. Normal ventricular septal motion in atrial septal defect. Mayo Clin Proc 1972; 47: 635-8.

17 Tajik AJ, Gau GT, Schattenberg TT. Echocardiogram in atrial septal defect with small left-to-right shunt. Chest 1973; 63: 95.

18 Kerber RE, Dippel WF, Abboud FM. Abnormal motion of the interventricular septum in right ventricular volume overload. Circulation 1973; 48: 86-96.

Requests for reprints to $\mathrm{Dr}$ Henrik Egeblad, Cardiovascular Laboratory of Medical Department B, Rigshospitalet, Blegdamsvej 9, 2100 Copenhagen $\varnothing$, Denmark. 